\title{
Rheological characterization of potassium carbonate deep eutectic solvent (DES) based drilling mud
}

\author{
Muhammad Hammad Rasool ${ }^{1}$ Asif Zamir ${ }^{1,2} \cdot$ Khaled A. Elraies $^{1} \cdot$ Maqsood Ahmad $^{1} \cdot$ Muhammad Ayoub $^{3}$. \\ Muhammad Adeem Abbas ${ }^{1} \cdot$ Imtiaz $^{1}$ Al $^{1}$
}

Received: 29 July 2021 / Accepted: 11 October 2021 / Published online: 25 November 2021

(c) The Author(s) 2021

\begin{abstract}
Different additives are added in the drilling mud to increase its efficiency in terms of its rheology and filtration properties. Recently, the application of ionic liquids (ILs) has been exploited by various investigators as a drilling additive for improving the mud rheology. The more recent studies have shown that imidazolium-based ionic liquids (the most used class of ionic liquids in drilling fluids) are toxic. Moreover, the advancement in green chemistry has put a big question mark on the greener nature of ionic liquids because they are non-biodegradable and generally very expensive. Deep eutectic solvents (DES) are the non-toxic and cheaper alternative of ionic liquids possessing the same qualities as of ILs. In our previous work, we used potassium carbonate and glycerol-based DES as a drilling fluid additive. We found that DES has successfully improved the mud rheology and filtration properties of the mud. In this current study, various characterizations have been conducted to understand the underlying mechanism behind DES as a rheology modifier. The characterization shows the improvement in rheology is due to the intercalation of DES between alumino-silicate layers and interaction of DES with clay which alters edge to face orientation of sodium bentonite and ultimately its dispersion behaviour. The addition of DES decreases average grain size and disperses the clay particles in mud slurry which reduce the overall permeability and porosity of the filter cake thus improving the filtration behaviour of the mud. Moreover, the behaviour of DES based mud is modelled at $25^{\circ} \mathrm{C}$ and $100{ }^{\circ} \mathrm{C}$ which shows DES-based mud follows Herschel-Buckley model and exhibits shear thinning behaviour even at elevated temperature.
\end{abstract}

Keywords Deep eutectic solvent $\cdot$ Drilling fluid additive $\cdot$ Mud rheology $\cdot$ Hydrates inhibition

$\begin{array}{ll}\text { Abbreviations } \\ \text { B.P.L } & \text { Bingham Plastic Law } \\ \text { DES } & \text { Deep Eutectic Solvent } \\ \text { G.S } & \text { Gel Strength } \\ \text { H.B.M/Y.P.L } & \text { Herschel-Buckley Model / Yield Power } \\ & \text { Law } \\ \text { ILs } & \text { Ionic Liquids } \\ \text { M.P.E } & \text { Mean Percentage Error } \\ \text { Na-Bt } & \text { Sodium Bentonite } \\ \text { P.L } & \text { Power Law }\end{array}$

Asif Zamir

asif.zamir@utp.edu.my

1 Petroleum Engineering Department, Universiti Teknologi PETRONAS, Bandar Seri Iskandar, Perak, Malaysia

2 Well Engineering Department, International College of Engineering and Management, Muscat, Oman

3 Chemical Engineering Department, Universiti Teknologi PETRONAS, Bandar Seri Iskandar, Perak, Malaysia

$\begin{array}{ll}\text { S.D } & \text { Standard Deviation } \\ \text { W.B.M } & \text { Water-Based Mud } \\ \text { YP/PV } & \text { Yield Point/Plastic Viscosity } \\ \text { Z.P } & \text { Zeta Potential }\end{array}$

\section{Introduction}

Drilling fluid design plays the most significant role in the whole drilling process. Drilling fluid behaves as a non-Newtonian fluid, and it demonstrates shear thinning behaviour (Rasool et al. 2021a). For a drilling fluid, apart from having necessary yield point and gel strength, the high viscosity is required when cuttings are transported to the surface, and low viscosity is needed when mud is passing through the drill string (Ofei et al. 2017).

Different kinds of additives are added in the drilling mud to enhance the rheological properties of the drilling mud (Rasool et al. 2021b). These additives mainly alter

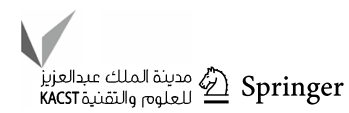


the chemical properties (related to hydrates inhibition and shale swelling) or mechanical properties which are related to the flow behaviour of the mud such as yield point and gel strength which govern the cutting transportation ability of the drilling mud (Ekeinde et al. 2019, Abbas et al. 2021).

Lately, ionic liquids are used as drilling fluid additives to enhance the rheological and improve the filtration properties of the drilling mud. Ionic liquids are low melting point liquids possessing negligible vapour pressure (Bavoh et al. 2020; Bera et al. 2020). Research has shown the addition of ionic liquids affects the clay structure which in turn alters its wettability which results into the modification of the mud rheology and its filtration behaviour (Ahmad, et al. 2019; Ahmed Khan et al. 2020).

Though ionic liquids have a lot of applications in drilling industry, there are certain disadvantages associated with the usage of ionic liquids which puts a question mark for its industrial usage. Ionic liquids are expensive, nonbiodegradable and hard to prepare as it requires sophisticated techniques and equipment for its preparation (Kunz and Häckl 2016). Moreover, study has shown that the most popular class of ionic liquids being used in drilling fluids, i.e. imidazolium-based ionic liquids, is toxic (Zhao et al. 2007; Romero et al. 2008; Pham et al. 2010; Egorova and Ananikov 2014). An alternative solvent is needed that holds all the required traits of ionic liquids and can be used as a drilling fluid additive.

Deep eutectic solvents (DES) are fourth-generation ionic liquids which are formulated by the combination of a hydrogen bond donor (HBD) and a hydrogen bond acceptor (HBA) (Naser et al. 2013). These HBA and HBD are mostly easily available salts or alcohols which are non-toxic and which on mixing together at a particular ratio and temperature gives a low melting point solvent which retains its physical state at broad range of temperature (Hansen et al. 2020).

\section{Previous study}

In our previous work, potassium carbonate (PC) and glycerol (Gly)-based deep eutectic solvent (DES) has been prepared in-house and its rheological properties have been measured (Rasool et al. 2021a). It has been observed that the addition of DES resulted into improving the yield point/plastic viscosity (YP/PV) of the mud nearer to the acceptable range of $0.75-1 \mathrm{lbm} / 100 \mathrm{ft}^{2} / \mathrm{cp}$. YP/PV is considered as one of the important indicators of mud rheology. Moreover, the DESbased mud also reduced the filtrate volume by $24 \%$ and mudcake thickness by $36 \%$ (Rasool et al. 2021b).

\section{Current study}

\section{Structural characterizations}

This research work focusses on the characterization of the DES-based drilling mud to understand the underlying mechanism behind DES as a rheology modifier. The characterizations are conducted to find the answers of the following questions.

1. Which mineral of clay will show more affinity towards DES?

2. What will be the effect of DES on d-spacing and mean crystalline size of clay?

3. What will be the effect of DES on stability of colloidal?

To answer the above-mentioned questions, FTIR, XRD and zeta potential of DES -WBM (water-based mud) are conducted.

\section{Rheological modelling}

The rheological models are essential for drilling mud rheology analysis because they are employed to stimulate the behaviour of drilling mud under different dynamic conditions (Skadsem et al. 2019). The rheological models can help us to predict and estimate the following applications/ behaviour (Wiśniowski et al. 2020):

- Frictional pressure losses in pipes and annuli

- Flow regimes

- Swab and surge pressure

- Hole cleaning efficiency

- Equivalent circulation density (ECD)

In this study, the best fit rheological model will be found out that best describes the behaviour of DES-WB.

\section{Shear thinning behaviour}

It is important for drilling mud to show shear thinning behaviour during its circulation for better hole cleaning and cutting transportation (Tchameni et al. 2021). This research will also focus on studying the shear thinning behaviour of mud at room temperature as well as at elevated temperature. 


\section{Materials and methods}

The method to prepare in-house DES, DES-WBM and finding the rheological and filtration properties of the drilling mud have been given in detail in our previous work (Rasool et al. 2021a).

\section{Characterization techniques}

\section{FTIR}

Fourier-transform infrared spectra (FTIR, Perkin Elmer) of DES-WBM (prepared under API 13B/1 guidelines) have been done to assess the interaction of DES with the clay.

\section{XRD}

The wet drilling mud samples with varying concentrations of DES have been used to investigate the intercalation of DES into the clay layers by using X-ray diffraction (XRD) analysis. The XRD peaks have been obtained by utilizing Benchtop X-ray diffractometer (D2 phaser) operating at $45 \mathrm{kV}$ and $40 \mathrm{~mA}$ with $\mathrm{Cu} \mathrm{K} \alpha$ radiation $(\lambda=1.54059 \AA)$. Bragg's equation was then applied to find the d-spacing. Moreover, the minerology of dry sodium bentonite as well as its d-spacing is also found out by using XRD analysis.

Mean crystalline size analysis The broadening of peak in $\mathrm{XRD}$ analysis can also be used to estimate the ordered mean crystalline size using Scherrer equation

$\tau=\frac{K \lambda}{\beta \cos \theta}$

where $\tau$ is mean ordered crystalline size which may be equal or smaller than the grain size, $\mathbf{K}=$ Scherrer's constant which is equal to $0.9, \boldsymbol{\beta}$ is $\mathrm{FWMH}$, i.e. the line broadening at half the full intensity, and $\theta$ is the Bragg's angle.

The crystalline size obtained from Eq. (1) may not be the true representation of numerical value of particle size, but it gives a generic idea about the trend in the overall size of the particle (Miranda and Sasaki 2018).

\section{Zeta potential}

The diluted drilling mud samples were used to measure zeta potential. ZP (zeta potential) of the dispersion was computed by Malvern Zetasizer Nano ZSP.

\section{Rheological modelling and shear thinning behaviour}

Rheological modelling is very significant in drilling fluid calculations because it helps in anticipating the behaviour of drilling fluid in dynamic conditions.

In this study, rheometer (DHR1) has been used to find shear stress and dynamic viscosity of DES-WBM at shear rates between 1.48 and $1200 \mathrm{~s}^{-1}$ at $25^{\circ} \mathrm{C}, 100{ }^{\circ} \mathrm{C}$. Drilling fluid shows non-Newtonian behaviour in which the viscosity changes with shear rate. There are three main models that are generally used to model the behaviour of the drilling mud (Moghaddam and Saadatabadi 2020).

1) Bingham Plastic Law (B.P.L)

2) Power Law (P.L)

3) Herschel-Buckley Model or Yield Power Law (Y.P.L)

The details and mathematical calculation of all these models can be found in the work of Folayan (2017) (Folayan et al. 2017). The best fit model is determined by curve fitting using two parameters mentioned below as Eqs. (2) and (3):

M.P.E. (Mean percentage error) 2. Standard deviation (S.D)

M.P.E. $=\frac{100}{n} \sum_{t=1}^{n} \frac{A t-F t}{A t}$

where $\mathrm{A}_{\mathrm{t}}$ is the actual value where $F_{t}$ is the forecasted value.

$\sigma=\sqrt{\frac{\sum\left(x_{i}-\bar{x}_{i}\right)^{2}}{N}}$

Table 1 Bentonite composition

\begin{tabular}{ll}
\hline Bentonite Composition & \\
\hline Smectite group & $47 \%$ \\
\hline Quartz & $29 \%$ \\
Carbonates & $9 \%$ \\
Ferric oxide & $4.7 \%$ \\
Hatrurite & $4 \%$ \\
Phosphates & $2.3 \%$ \\
Sodium oxide & $1.83 \%$ \\
Iron Silicates & 2.17 \\
Smectite Composition & \\
Montmorillonite & $88.6 \%$ \\
Beidellite & $10.1 \%$ \\
Silver Alumino-silicates & $1.2 \%$ \\
Trace elements & $0.1 \%$ \\
\hline
\end{tabular}


where $\sigma$ is standard deviation, $x_{i}$ is each value from the data set, $\bar{x}_{i}$ is mean of the whole population and $\mathrm{N}$ is the size of the population.

\section{Results and discussion}

\section{Minerology of dry sodium bentonite (Clay)}

The X-ray diffraction analysis was used to find the mineralogical composition of clay. Table 1 shows the mineralogical quantification of clay. The clay contains $47 \%$ smectite group which further had $88.6 \%$ of Montmorillonite. The Montmorillonite is mainly comprised of tetrahedral and octahedral sheets alumina and silica which has the dominant percentage of silica (Uddin 2018).

\section{FTIR analysis of DES based mud}

In FTIR spectrum, the y-axis represents $\%$ transmittance which shows the intensity of the Infrared radiation with respect to the reference. Low transmittance percentage means that there are huge number of bonds whose vibrational energies correspond to the incident light and reverse is true for high transmittance percentage. Also, the $\mathrm{x}$-axis shows wave number which corresponds to a particular functional group. The change in wave number corresponds to the change in electronegativity difference which depicts the formation of a bond (Nandiyanto et al. 2019). Generally, the clay (Na-MMT) contains dominant percentage of silica and alumina in its composition which are represented by peaks $1032 \mathrm{~cm}^{-1}$ and $634.3 \mathrm{~cm}^{-1}$, respectively (Majdan et al. 2005).

FTIR spectrum of blank/base mud sample and DESbased samples shows DES didn't show any affinity towards silica mineral as there hasn't been any change in wave number $1032 \mathrm{~cm}^{-1}$ (silica) for base sample as well as DESbased samples. The change in wavenumbers from 634.3 to $648.4 \mathrm{~cm}^{-1}$ (0.1\% DES), $632.3 \mathrm{~cm}^{-1}(0.5 \%$ DES) and $605 \mathrm{~cm}^{-1}$ (1\% DES) shows the interaction between clay (alumina mineral) and added DES as shown in Fig. 1. The irregular decrement and increment are due to the different population of bonds present in different percentages of DES.

This FTIR confirms that DES has shown affinity towards clay surface by bonding onto it. However, the phenomenon of intercalation will be confirmed by XRD analysis (Seidl et al. 2017).

\section{D-spacing analysis of DES based mud}

XRD analysis of dry Na-Bt (sodium bentonite), base mud (hydrated Na-Bt) and DES-based mud samples in terms of $\mathrm{d}$-spacing proved to be very conclusive. D-spacing is an important factor in deciding if any added solvent will have any affinity towards clay or not (Manoratne et al. 2017). $\mathrm{D}$-spacing is a function of clay layer and interlayer cations, e.g. kaolinite has no interlayer cations; thus, its d-spacing value will be less than smectite which has inter-layer cations

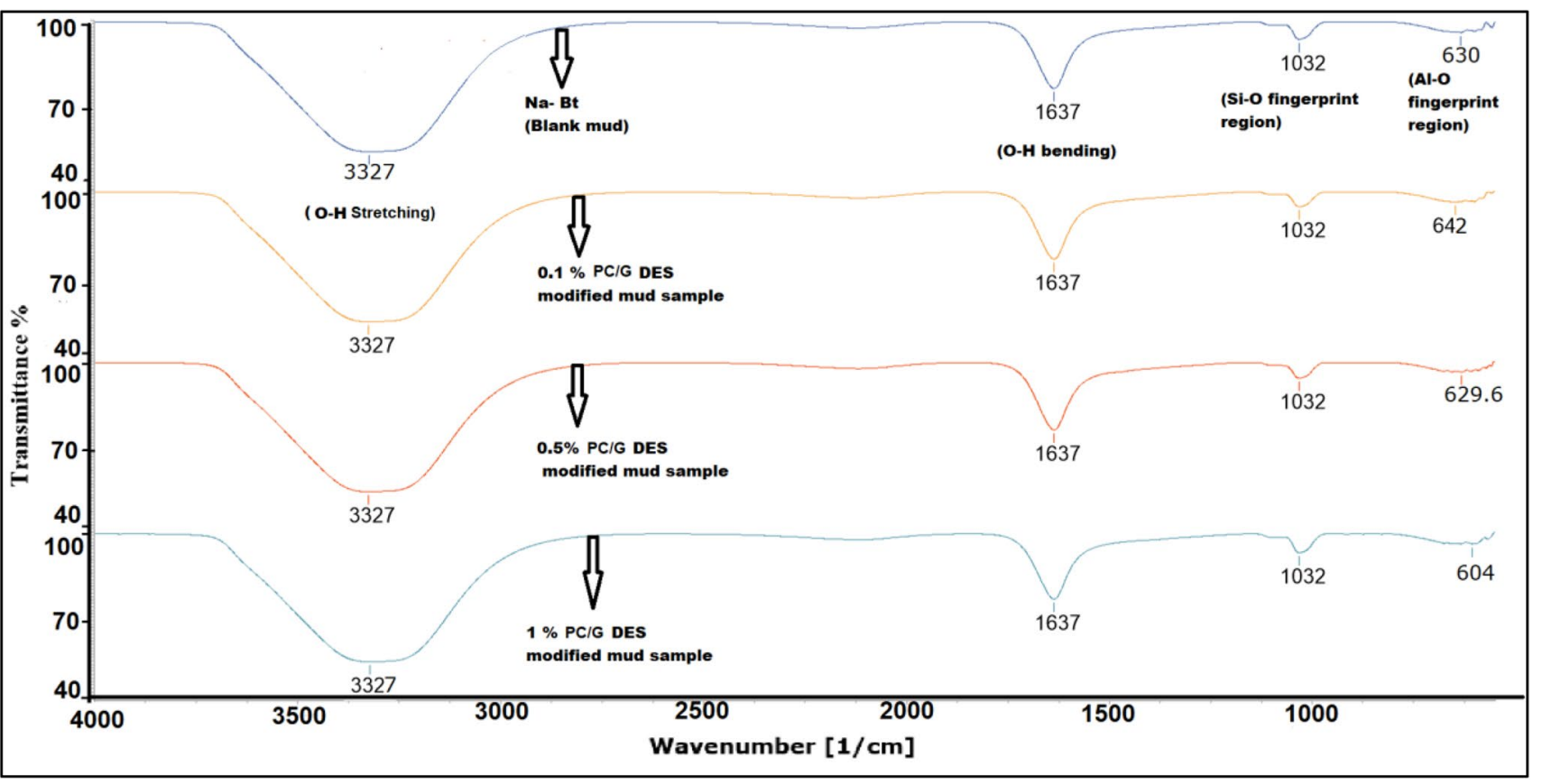

Fig. 1 FTIR spectra DES-PC:Gly-based mud at various conc 
Fig. 2 d-spacing analysis of Dry $\mathrm{Na}-\mathrm{Bt}$, base sample and DESbased mud

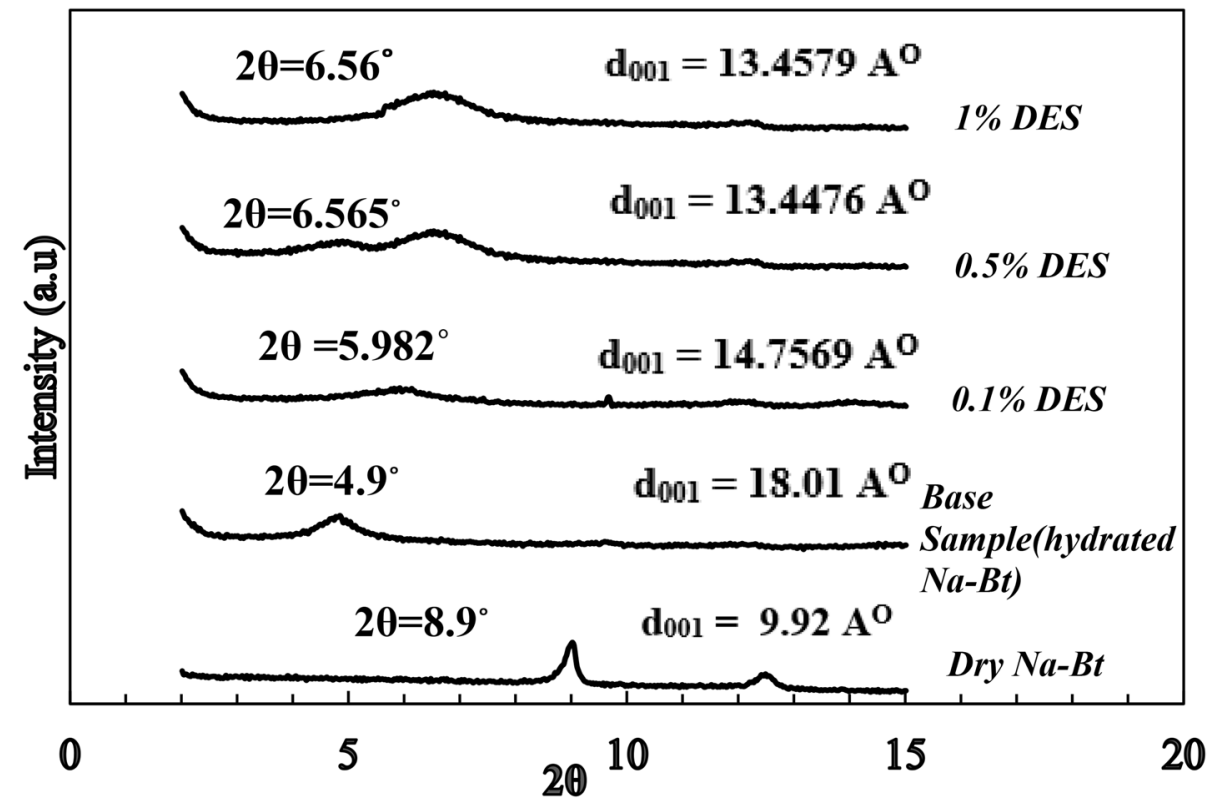

Table 2 Effect of DES on mean clay size

\begin{tabular}{ll}
\hline Sample & Mean Grain Size \\
\hline Dry Na-Bt & $336 \mathrm{~nm}$ \\
Base sample & $434.81 \mathrm{~nm}$ \\
$0.1 \%$ DES-WBM & $379.42 \mathrm{~nm}$ \\
$0.5 \%$ DES-WBM & $355.80 \mathrm{~nm}$ \\
$1 \%$ DES-WBM & \\
\hline
\end{tabular}

present (Ahmad et al. 2019). The addition of water hydrates the cation, thus causing an increase in d-spacing values (Moore and Hower 1986).

For wet drilling mud samples, water is present between the alumino-silicate layers, and if the added solvent possesses more affinity towards clay than water, it will expel the water and hydrated cations out of the clay layers while decreasing the d-spacing ( $\mathrm{Jia}$ et al. 2019; Weichao et al. 2021).

XRD results show $\mathrm{d}_{001}$ of the dry Na-Bt came out to be $9.92 \mathrm{~A}^{\mathrm{o}}$ which increased to $18.01 \mathrm{~A}^{\mathrm{o}}$ after adding water (base sample) as shown in Fig. 2. The addition of DES decreased the d-spacing to $14.756 \mathrm{~A}^{\circ}$ at $0.1 \%$. This further decreased to $13.45 \mathrm{~A}^{\circ}$ at $0.5 \%$. It became nearly constant at $1 \% \mathrm{DES}$ which means that DES can't replace the water from between alumino-silicate layers anymore.

\section{Effect of DES on average grain size of clay}

The average grain size of the clay particles has been found to understand the effect of DES on clay granules using method mentioned in Sect. 2.1.2.1. From Table 2, it can be seen that the average grain size of the clay increases from 336 to
Table 3 Relation between zeta potential values and stability (Kumar and Dixit 2017)

\begin{tabular}{ll}
\hline Zeta Potential Value & Stability \\
\hline $0- \pm 5$ & Rapid flocculation \\
$\pm 10- \pm 30$ & Instability \\
$\pm 30- \pm 40$ & Average stability \\
$\pm 40- \pm 60$ & Good stability \\
$>61$ & Marvelous stability \\
\hline
\end{tabular}

$434.81 \mathrm{~nm}$ when it is hydrated which grdually decreases on addition of DES. The base sample conatins water present between the alluminio-silicate layers which is explelled on the addition of DES into the mud slurry. This expulsion of water between the clay layers indicates that DES shows more affinity towards clay than water, hence expelling water from the clay layers.

The results of avegare grain size are in accordance with the d-spacing calculated for dry $\mathrm{Na}-\mathrm{Bt}$, wet mud slurry and DES-based mud samples.

\section{Zeta potential}

Zeta potential is an important parameter in dictating the stability of the dispersion in any colloidal. The magnitude of the zeta potential shows the electrostatic repulsion between same sizes particles in any colloidal. When the zeta potential is small, the attractive forces may overcome the repulsive forces which will result into the flocculation of the dispersion, thus disrupting the stability of the colloidal. So, the dispersions with small zeta potential values tend to 
flocculate while the higher values of Z.P. will tend to avoid the flocculation thus making the colloidal more stable.

In this research, zeta potential of the base mud and DESbased mud samples has been measured. The colloidal is said to be stable when its zeta potential value is higher than $30 \mathrm{mV}$ as tabulated in Table 3. From the results, it can be seen that the base mud sample is stable.

For potassium carbonate-based DES, it can be seen that the dispersion becomes more stable with the addition of DES. However, at $0.5 \%$, the zeta potential value rose to $-42.9 \mathrm{mV}$ which indicates at this higher value the solution of dispersion will suppress aggregation thus conferring good stability to the colloidal as shown in Fig. 3.

\section{Discussion on mechanism behind DES as a drilling fluid additive}

\section{Mechanism behind improvement in rheological properties}

Sodium bentonite (Na-Bt) possesses a specific face to edge structure in which face is attracted to the edge giving rise to a special 'house of card' structure. This structure is responsible to grant specific properties to the drilling mud suspension. The DES attaches/bonds to the clay surface and intercalates into clay layers decreasing the d-spacing as shown in Fig. 4 which hinders the so-called face and edge surfaces to attract each other and formulate the "house of card' structure.

From Fig. 4, it can be seen that the d-spacing increases when dry Na-Bt is added into water as water intercalates between clay layers increasing the d-spacing. The addition of DES expels water between the hydrated clay layers and keeps on intercalating till the maximum exchange has occurred causing a decline in $\mathrm{d}$-spacing values.

This attraction between Na-Bt and DES disturbs the inherent structure of Na-Bt dispersion which changes the yield point and viscosity of the mud (Rasool et al. 2021b).

\section{Mechanism behind improvement in filtration properties}

It is desirable to design a mud slurry which will give low permeable mud cakes which indicates good filterability. Relatively, smaller grain particles give good filtration properties because their compacted structure offers less permeability which improves the filtration behaviour (Zhang 2017). Moreover, the filtration behaviour of drilling mud is strongly controlled by its ability to flocculate, dispersed and deflocculated. The advantageous scenario is when the $\mathrm{Na}-\mathrm{Bt}$ particles in the slurry are dispersed and deflocculated as the small clay particles will offer low porosity and permeability (Kelessidis et al. 2007).

From Table 2 and Fig. 4, it can be seen that the addition of DES in the mud slurry decreases the average grain size of bentonite. Moreover, Fig. 3 shows how the addition of DES increases the zeta potential on clay surface which hinders its ability to flocculate, thus giving a good dispersion. Thus, the addition of the DES in the mud slurry disperses the clay particles which reduce the permeability and porosity of the filter cake, thus improving the overall filtration behaviour of the drilling mud (Feng et al. 2021).
Fig. 3 Zeta potential of PC:Glybased mud at various conc

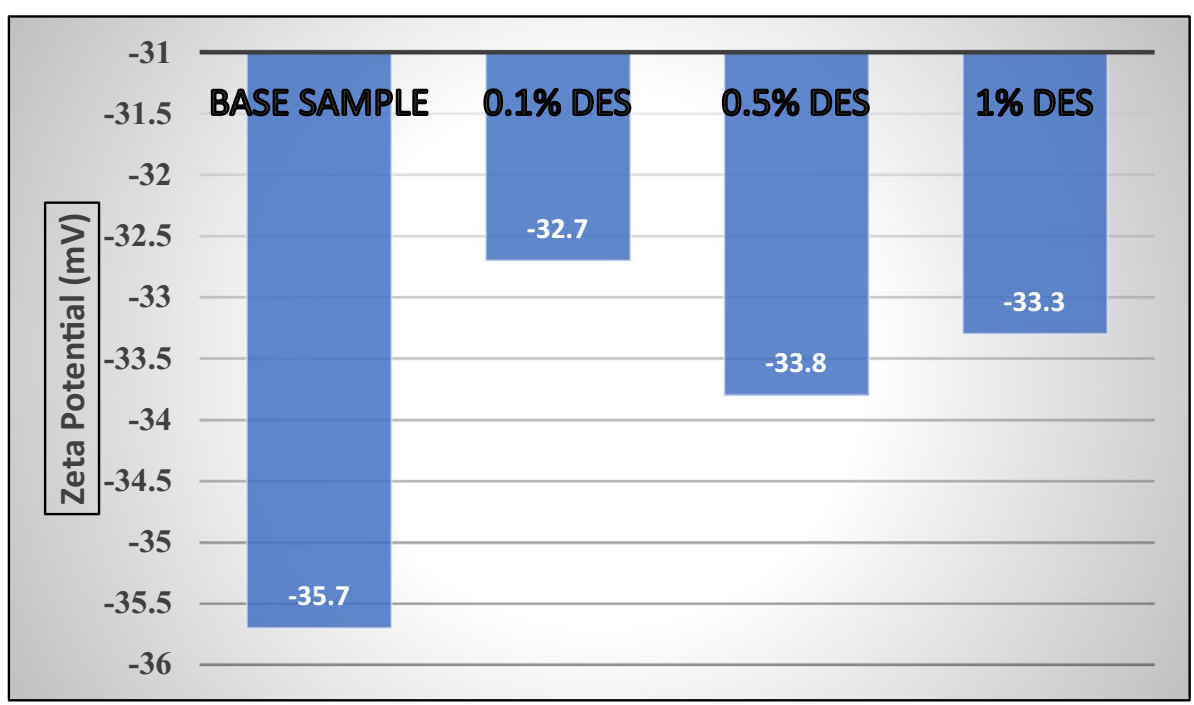




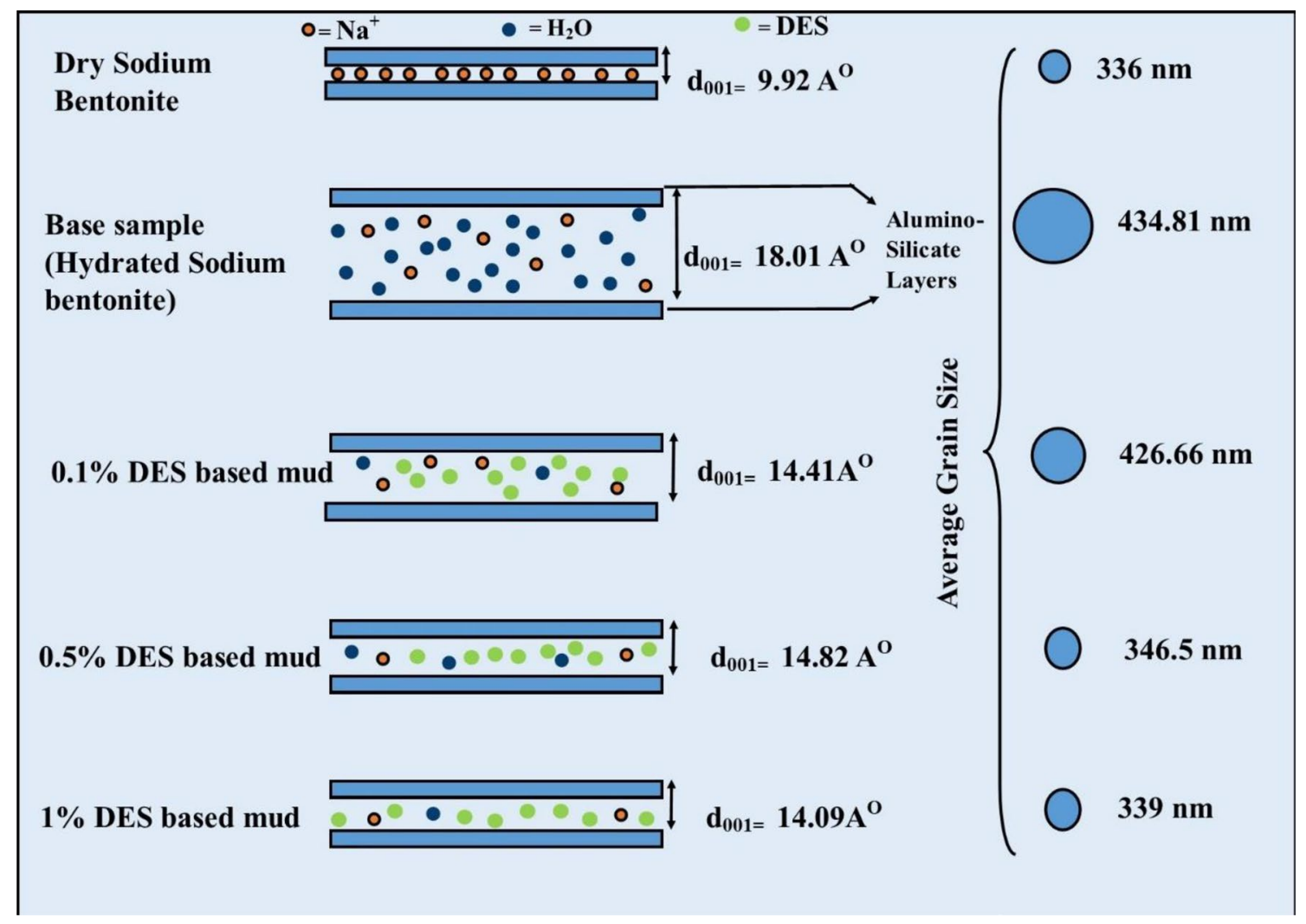

Fig. 4 Illustration of effect of PC:Gly-DES on intercalation and average gran size of mud

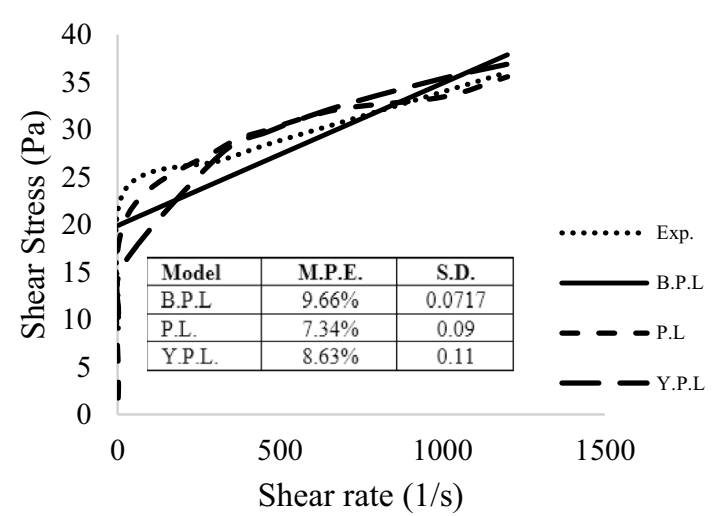

Fig. 5 Shear rate vs shear stress for base sample at $25^{\circ} \mathrm{C}$

\section{Rheological modelling and shear thinning behaviour of mud}

It is very important to find the right rheological model to exactly simulate the behaviour of drilling mud under dynamic conditions. M.P.E. and standard deviations (Eqs. 2 and 3 ) of all three rheological models have been determined for curve fitting as shown in Figs. 5, 6, 7, 8, 9, 10, 11, 12.

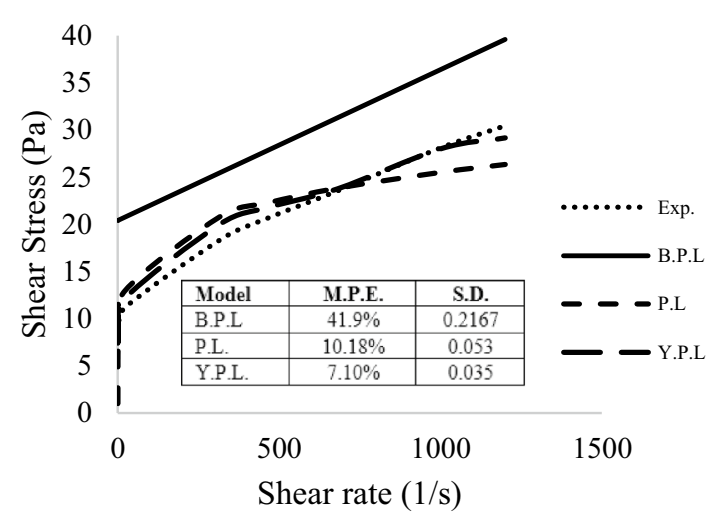

Fig. 6 Shear rate vs shear stress for 0.1\% PC:Gly-based sample at $25^{\circ} \mathrm{C}$

Table 4 shows that the base sample follows power law while DES-based mud follows Y.P.L (Herschel-Buckley model) at $25^{\circ} \mathrm{C}$ and $100{ }^{\circ} \mathrm{C}$ which is the best model because it incorporates the yield stress even at lower shear rates. 


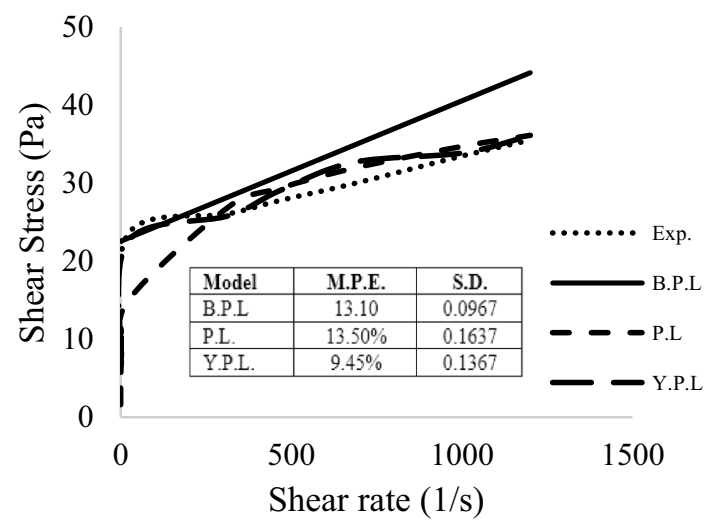

Fig. 7 Shear rate vs shear stress for $0.5 \%$ PC:Gly-based sample at $25^{\circ} \mathrm{C}$

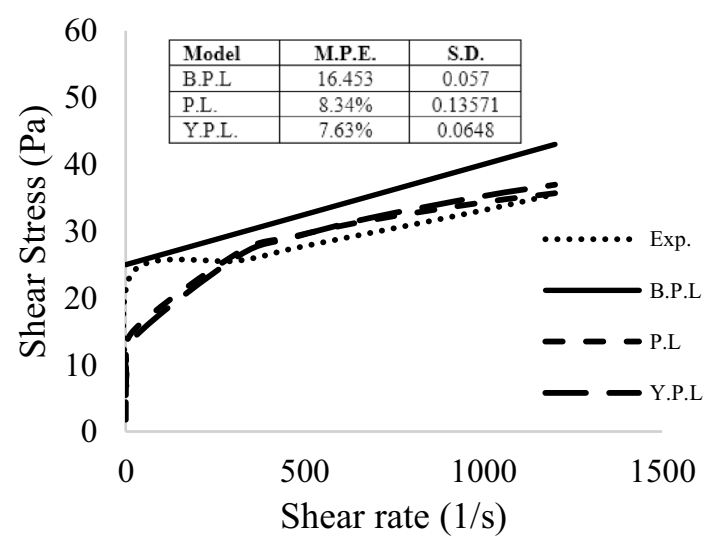

Fig. 8 Shear rate vs shear stress for $1 \%$ PC:Gly-based sample at $25^{\circ} \mathrm{C}$

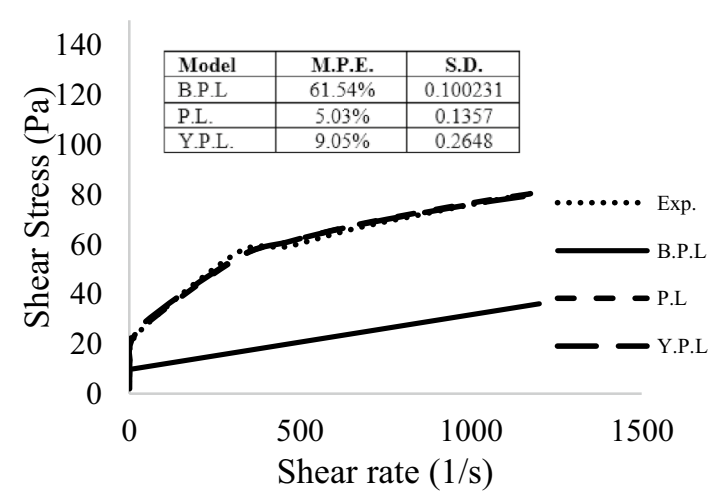

Fig. 9 Shear rate vs shear stress for base sample at $100{ }^{\circ} \mathrm{C}$

\section{Shear thinning behaviour}

It is important for drilling mud to show thixotropic behaviour such as varying viscosity with time in order to perform certain functions such as circulation and cutting transportation.

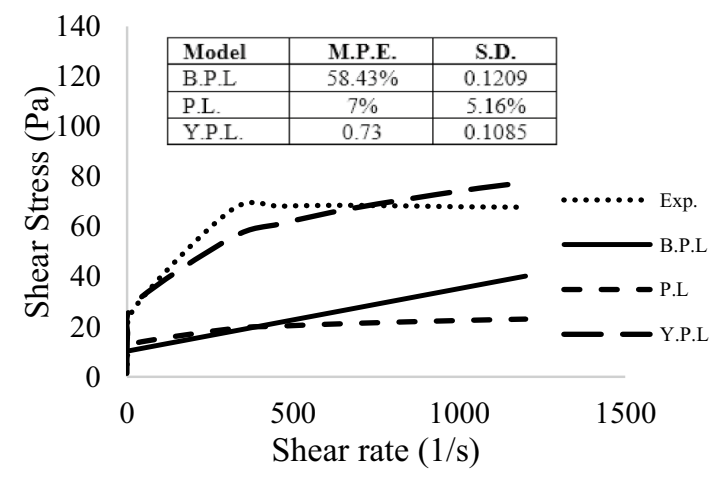

Fig. 10 Shear rate vs shear stress for 0.1\% PC:Gly-based sample at $100{ }^{\circ} \mathrm{C}$

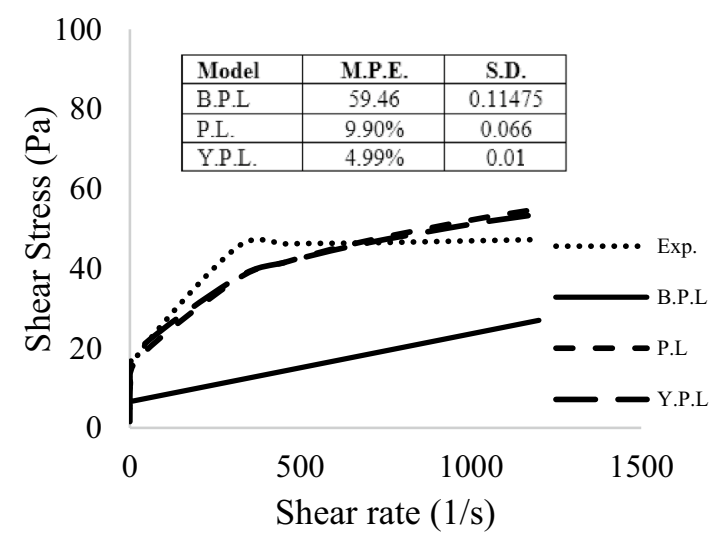

Fig. 11 Shear rate vs shear stress for $0.5 \%$ PC:Gly-based sample at $100{ }^{\circ} \mathrm{C}$

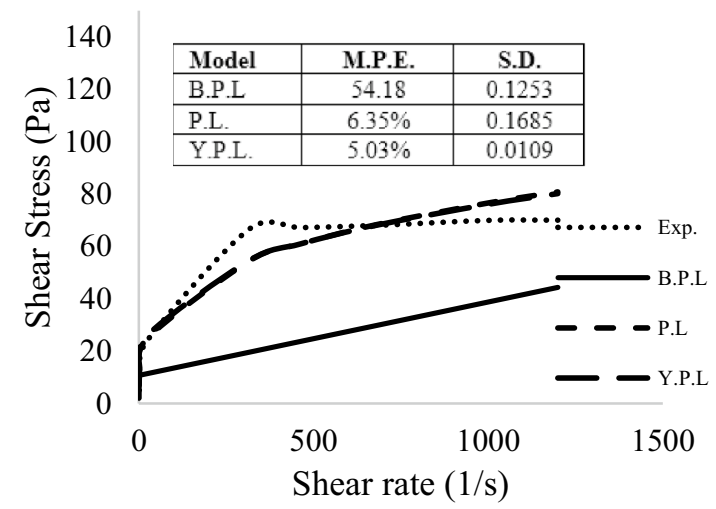

Fig. 12 Shear rate vs shear stress for $1 \%$ PC:Gly-based sample at $100{ }^{\circ} \mathrm{C}$

The current research shows that DES-based mud exhibits predictable shear thinning behaviour as shown in Figs. 13 and 14. The effect of elevated temperature on shear thinning behaviour of the mud is shown in Fig. 14. 
Table 4 Rheological curve fitting

\begin{tabular}{|c|c|c|c|c|c|c|c|}
\hline \multirow[t]{2}{*}{ Conc. $\%$} & \multicolumn{4}{|l|}{$25^{\mathrm{O}} \mathrm{C}$} & \multicolumn{3}{|l|}{$100^{\circ} \mathrm{C}$} \\
\hline & B.P.L & & P.L & Y.P.L & B.P.L & P.L & Y.P.L \\
\hline \multirow[t]{3}{*}{ Base sample } & $\begin{array}{l}\mathrm{YP}=19.89 \mathrm{~Pa} \\
\mathrm{PV}=0.015 \mathrm{~Pa} . \mathrm{s}\end{array}$ & & $\begin{array}{l}\mathrm{K}=9.953 \\
\mathrm{n}=0.179\end{array}$ & $\begin{array}{l}K=4.8261 \\
n=0.266\end{array}$ & $\begin{array}{l}\mathrm{YP}=9.69 \mathrm{~Pa} \\
\mathrm{PV}=0.022 \mathrm{~Pa} . \mathrm{s}\end{array}$ & $\begin{array}{l}\mathrm{K}=9.842 \\
\mathrm{n}=0.2968\end{array}$ & $\begin{array}{l}K=9.5323 \\
n=0.2969\end{array}$ \\
\hline & M.P.E & $9.66 \%$ & $7.34 \%$ & $8.63 \%$ & $61.54 \%$ & $5.03 \%$ & $9.05 \%$ \\
\hline & S.D & 0.717 & 0.09 & 0.11 & 0.1002 & 0.13571 & 0.2648 \\
\hline \multirow[t]{3}{*}{$0.10 \%$} & $\begin{array}{l}\mathrm{YP}=20.4 \mathrm{~Pa} \\
\mathrm{PV}=0.016 \mathrm{~Pa} . \mathrm{s}\end{array}$ & & $\begin{array}{l}K=7.52 \\
n=0.1768\end{array}$ & $\begin{array}{l}\mathrm{K}=2.3104 \\
\mathrm{n}=0.3115\end{array}$ & $\begin{array}{l}\mathrm{YP}=10.2 \mathrm{~Pa} \\
\mathrm{PV}=0.025 \mathrm{~Pa} . \mathrm{s}\end{array}$ & $\begin{array}{l}\mathrm{K}=8.77 \\
\mathrm{n}=0.1359\end{array}$ & $\begin{array}{l}\mathrm{K}=10.5949 \\
\mathrm{n}=0.2714\end{array}$ \\
\hline & M.P.E & $41.9 \%$ & $10.18 \%$ & $7.10 \%$ & $58.43 \%$ & $7 \%$ & $5.16 \%$ \\
\hline & S.D & 0.2167 & 0.053 & 0.035 & 0.1209 & 0.73 & 0.1085 \\
\hline \multirow[t]{3}{*}{$0.50 \%$} & $\begin{array}{l}\mathrm{YP}=22.5 \mathrm{~Pa} \\
\mathrm{PV}=0.018 \mathrm{~Pa} . \mathrm{s}\end{array}$ & & $\begin{array}{l}K=7.59 \\
n=0.22\end{array}$ & $\begin{array}{l}K=2.69 \\
n=0.3635\end{array}$ & $\begin{array}{l}\mathrm{YP}=6.63 \mathrm{~Pa} \\
\mathrm{PV}=0.017 \mathrm{~Pa} . \mathrm{s}\end{array}$ & $\begin{array}{l}\mathrm{K}=7.12 \\
\mathrm{n}=0.2883\end{array}$ & $\begin{array}{l}K=6.576 \\
n=0.286\end{array}$ \\
\hline & M.P.E & $13.10 \%$ & $13.50 \%$ & $9.45 \%$ & $59.46 \%$ & $9.90 \%$ & $4.99 \%$ \\
\hline & S.D & 0.0967 & 0.1637 & 0.1367 & 0.1147 & 0.066 & 0.01 \\
\hline \multirow[t]{3}{*}{$1 \%$} & $\begin{array}{l}\mathrm{YP}=24.99 \mathrm{~Pa} \\
\mathrm{PV}=0.015 \mathrm{~Pa} . \mathrm{s}\end{array}$ & & $\begin{array}{l}\mathrm{K}=7.836 \\
\mathrm{n}=0.2137\end{array}$ & $\begin{array}{l}\mathrm{K}=4.58 \\
\mathrm{n}=0.2819\end{array}$ & $\begin{array}{l}\mathrm{YP}=10.71 \mathrm{~Pa} \\
\mathrm{PV}=0.028 \mathrm{~Pa} . \mathrm{s}\end{array}$ & $\begin{array}{l}\mathrm{K}=9.842 \\
\mathrm{n}=0.2968\end{array}$ & $\begin{array}{l}K=6.576 \\
n=0.2965\end{array}$ \\
\hline & M.P.E & $16.453 \%$ & $8.34 \%$ & $7.63 \%$ & $54.18 \%$ & $6.35 \%$ & $5.03 \%$ \\
\hline & S.D & 0.057 & 0.13571 & 0.0648 & 0.1235 & 0.1685 & 0.0109 \\
\hline
\end{tabular}

The selected rheological model based upon the lowest M.P.E and S.D can be seen in the bold text

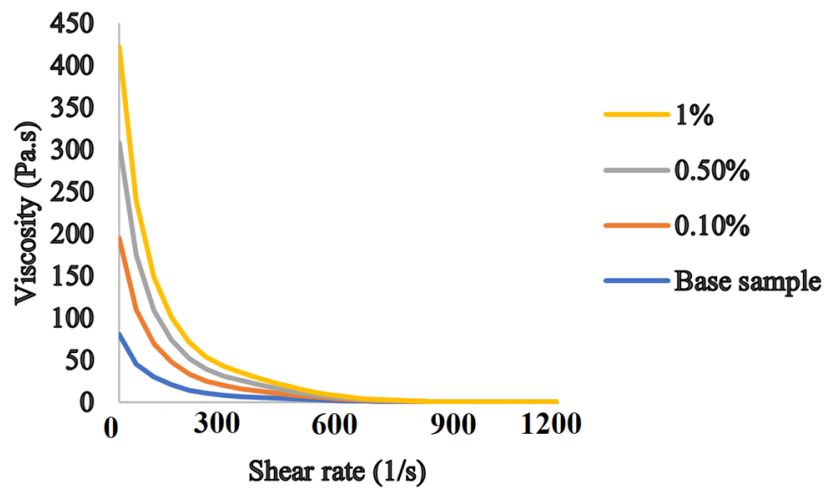

Fig. 13 Shear thinning behaviour of DES-based mud at $25^{\circ} \mathrm{C}$

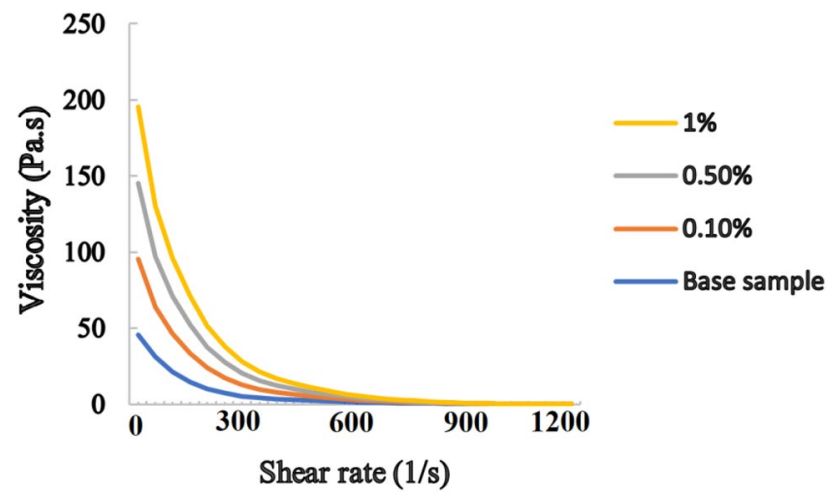

Fig. 14 Shear thinning behaviour of DES-based mud at $100{ }^{\circ} \mathrm{C}$

The elevated temperature causes a decrement in dynamic viscosity due to decrease in intermolecular attraction.

However, the DES-based mud retains its shear thinning behaviour at elevated temperature.

\section{Conclusion}

1. Potassium carbonate-based DES is successful in improving rheology as well as the filtration behaviour of the mud.

2. Potassium carbonate-based DES interacted with clay and successfully intercalated between clay layers, reducing d-spacing which modified its rheology.

3. XRD showed that average grain size decreases with the addition of DES.

4. The smaller grain size will result into lesser permeable and porous mud cake. Moreover, the higher zeta potential values will hinder the clay particles to flocculate which will result into a better dispersion and thus improved filtration behaviour.

5. PC-based DES follows Herschel-Buckley's model and exhibits good shear thinning behaviour even at an elevated temperature of $100^{\circ} \mathrm{C}$.

Funding This research has been done under Y-UTP grant 015LC0-150.

\section{Declarations}

Conflict of interests The authors don't have any conflict of interest to declare. 
Ethics approval This research work doesn't include any testing on any sort of living beings nor does it cause any environmental concern.

Open Access This article is licensed under a Creative Commons Attribution 4.0 International License, which permits use, sharing, adaptation, distribution and reproduction in any medium or format, as long as you give appropriate credit to the original author(s) and the source, provide a link to the Creative Commons licence, and indicate if changes were made. The images or other third party material in this article are included in the article's Creative Commons licence, unless indicated otherwise in a credit line to the material. If material is not included in the article's Creative Commons licence and your intended use is not permitted by statutory regulation or exceeds the permitted use, you will need to obtain permission directly from the copyright holder. To view a copy of this licence, visit http://creativecommons.org/licenses/by/4.0/.

\section{References}

Abbas, M. A., A. Zamir, K. A. Elraies, S. M. Mahmood and M. H. Rasool (2021). "A critical parametric review of polymers as shale inhibitors in water-based drilling fluids." Journal of Petroleum Science and Engineering: 108745.

Ahmad HM, Kamal MS, Murtaza M, Khan S, Al-Harthi M (2019) Alteration of wettability and hydration properties of shale using ionic liquids in water-based drilling fluids. Abu Dhabi International Petroleum Exhibition \& Conference, Society of Petroleum Engineers. https://doi.org/10.2118/197940-MS

Ahmed Khan R, Murtaza M, Abdulraheem A, Kamal MS, Mahmoud M (2020) Imidazolium-based ionic liquids as clay swelling inhibitors: mechanism, performance evaluation, and effect of different anions. ACS Omega 5(41):26682-26696

Bavoh CB, Ofei TN, Lal B (2020) Investigating the potential cuttings transport behavior of ionic liquids in drilling mud in the presence of sii hydrates. Energy Fuels 34(3):2903-2915

Bera A, Agarwal J, Shah M, Shah S, Vij RK (2020) Recent advances in ionic liquids as alternative to surfactants/chemicals for application in upstream oil industry. J Ind Eng Chem 82:17-30

Egorova KS, Ananikov VP (2014) Toxicity of ionic liquids: eco (cyto) activity as complicated, but unavoidable parameter for task-specific optimization. Chemsuschem 7(2):336-360

Ekeinde EB, Okoro EE, Dosunmu A, Iyuke S (2019) Optimizing aqueous drilling mud system viscosity with green additives. J Pet Explor Prod Technol 9(1):315-318

Feng, Z., Y. Fan, X. Dong, X. Ma and R. Chen (2021). "Permeability estimation in filter cake based on X-ray microtomography Lattice Boltzmann Method." Separation and Purification Technology: 119114.

Folayan JA, Anawe PAL, Abioye PO, Elehinafe FB (2017) Selecting the most appropriate model for rheological characterization of synthetic based drilling mud. Int J Appl Eng Res 12(18):7614-7649

Hansen BB, Spittle S, Chen B, Poe D, Zhang Y, Klein JM, Horton A, Adhikari L, Zelovich T, Doherty BW (2020) Deep eutectic solvents: a review of fundamentals and applications. Chem Rev 121(3):1232-1285

Jia H, Huang P, Wang Q, Han Y, Wang S, Zhang F, Pan W, Lv K (2019) Investigation of inhibition mechanism of three deep eutectic solvents as potential shale inhibitors in water-based drilling fluids. Fuel 244:403-411

Kelessidis V, Tsamantaki C, Pasadakis N, Repouskou E, Hamilaki E (2007) Permeability, porosity and surface characteristics of filter cakes from water-bentonite suspensions. WIT Trans Eng Sci $56: 173-182$

Kumar, A. and C. K. Dixit (2017). Methods for characterization of nanoparticles. Advances in nanomedicine for the delivery of therapeutic nucleic acids, Elsevier: 43-58.

Kunz W, Häckl K (2016) The hype with ionic liquids as solvents. Chem Phys Lett 661:6-12

Majdan M, Maryuk O, Pikus S, Olszewska E, Kwiatkowski R, Skrzypek H (2005) Equilibrium, FTIR, scanning electron microscopy and small wide angle X-ray scattering studies of chromates adsorption on modified bentonite. J Mol Struct 740(1-3):203-211

Manoratne C, Rosa S, Kottegoda I (2017) XRD-HTA, UV visible, FTIR and SEM interpretation of reduced graphene oxide synthesized from high purity vein graphite. Mater Sci Res India 14(1):19-30

Miranda M, Sasaki J (2018) The limit of application of the Scherrer equation. Acta Crystallogr Sect a: Found Adv 74(1):54-65

Moghaddam AK, Saadatabadi AR (2020) Rheological modeling of water based drilling fluids containing polymer/bentonite using generalized bracket formalism. J Pet Sci Eng 189:107028

Moore D, Hower J (1986) Ordered interstratification of dehydrated and hydrated Na-smectite. Clays Clay Miner 34(4):379-384

Nandiyanto ABD, Oktiani R, Ragadhita R (2019) How to read and interpret FTIR spectroscope of organic material. Indones J Sci Technol 4(1):97-118

Naser J, Mjalli F, Jibril B, Al-Hatmi S, Gano Z (2013) Potassium carbonate as a salt for deep eutectic solvents. Int J Chem Eng Appl 4(3): 114

Ofei TN, Bavoh CB, Rashidi AB (2017) Insight into ionic liquid as potential drilling mud additive for high temperature wells. J Mol Liq 242:931-939

Pham TPT, Cho C-W, Yun Y-S (2010) Environmental fate and toxicity of ionic liquids: a review. Water Res 44(2):352-372

Rasool, M. H., A. Zamir, K. A. Elraies, M. Ahmad, M. Ayoub and M. A. Abbas (2021). "Investigative review on cutting transportation ability of ionic liquid-based drilling mud." J Hunan Univ Nat Sci 48(2).

Rasool, M. H., A. Zamir, K. A. Elraies, M. Ahmad, M. Ayoub and M. A. Abbas (2021). "Potassium carbonate based deep eutectic solvent (DES) as a potential drilling fluid additive in deep water drilling applications." Pet Sci Technol: 1-20.

Romero A, Santos A, Tojo J, Rodríguez A (2008) Toxicity and biodegradability of imidazolium ionic liquids. J Hazard Mater 151(1):268-273

Seidl L, Bucher N, Chu E, Hartung S, Martens S, Schneider O, Stimming U (2017) Intercalation of solvated Na-ions into graphite. Energy Environ Sci 10(7):1631-1642

Skadsem HJ, Leulseged A, Cayeux E (2019) Measurement of drilling fluid rheology and modeling of thixotropic behavior. Applied Rheology 29(1):1-11

Tchameni AP, Xie B, Nagre RD, Li T (2021) Investigating the thermal effect on the flow characteristics of acrylamide-based polymer modified bentonite drilling mud using upper shear stress limit. Energy Sources, Part a: Recovery, Utilization, Environ Eff 43(3):291-303

Uddin, F. (2018). Montmorillonite: An introduction to properties and utilization, IntechOpen London.

Weichao D, Xiangyun W, Taifei B, Man L, Zhang J, Gang C (2021) Synthesis and inhibitive mechanism of a novel clay hydration inhibitor for water-based drilling fluids. Mater Sci 27(2):210-216

Wiśniowski R, Skrzypaszek K, Małachowski T (2020) Selection of a suitable rheological model for drilling fluid using applied numerical methods. Energies 13(12):3192 
Zhang, J. (2017). Effects of porosity and permeability on invasion depth during drilling mud-filtrate invading into a reservoir dynamically. 7th International Conference on Education, Management, Information and Mechanical Engineering.

Zhao, D., Y. Liao and Z. Zhang (2007). "Toxicity of ionic liquids." Clean-soil, air, water, 35(1): 42-48.
Publisher's Note Springer Nature remains neutral with regard to jurisdictional claims in published maps and institutional affiliations. 